\title{
Evaluation of quality characteristics of beer by addition of rice rate
}

\author{
Seuk Ki Lee. Ji-Young Park, Hye-Young Park, Hye Sun Choi, Donghwa Cho, \\ Sea-Kwan Oh, Hyun-Joo Kim* \\ Department of Central Area Crop Science, National Institute of Crop Science, Rural Development Administration, \\ Suwon 16613, Korea
}

\section{쌀 첨가비율에 따른 맥주의 품질 특성 평가}

\author{
이석기 · 박지영 · 박혜영 · 최혜선·조동화·오세관·김현주* \\ 국립식량과학원 중부작물부 수확후이용과
}

\begin{abstract}
In this study the effect of rice addition on the quality of beer was investigated. Pilot-scale brews were performed with addition ratios of $10,20,30$, and $40 \%$ of brown rice (Oryza sativa L. cv. Hangaru) which were compared with $100 \%$ malt beer and commercial beers in terms of quality. Alcohol content of beer was between 3.93 to $4.40 \%$. The total sugar content increased when the rice percent was increased. The $\mathrm{pH}$ range of beer were 4.32 and 4.60, which were no significant differences found among by the rate of rice added. Total acidity and amino-acidity decreased corresponding to increasing percent of rice, on the other hand, lightness of beer was increased the increase in percent of rice, while redness and yellowness of beer were decreased. The study demonstrated that the increases of rice addition in beer provided some positive effects on beer quality by decreasing bitterness where as improving beer color
\end{abstract}

Key words : rice, beer, rice rate, quality

\section{서 론}

국내 주류시장은 경제발전과 함께 꾸준히 성장해왔으며, 맥주는 2014년도 국세청 기준 전체 주류 출고량의 $55.1 \%$ 로 가장 높은 비중을 차지하고 있다(1). 최근 수입맥주시장의 급성장으로 2014년 맥주 수입은 관세청 추산 1억 1천만불 규모로 연평균 $23.2 \%$ 증가하고 있으며(2), 이러한 시장 다 변화에 따라 좀 더 다양한 제품에 대한 소비자들의 요구가 높아지고 있다(3).

벼(Rice, Orzya sativa L.)는 우리나라를 비롯한 아시아권 을 중심으로 주식으로 섭취하고 있는 대표 작물 중 하나이 다. 하지만 식생활의 서구화 등으로 인한 다양한 사회적

*Corresponding author. E-mail : trrtod@korea.kr Phone : 82-31-695-0614, Fax : 82-31-695-4085

Received 28 August 2017; Revised 11 September 2017; Accepted 19 September 2017.

Copyright (c) The Korean Society of Food Preservation. All rights reserved.
변화로 인하여 1 인당 양곡소비량은 2011년 $71.2 \mathrm{~kg}$ 에서 2016년 $61.9 \mathrm{~kg}$ 으로 매년 약 1-2 kg씩 감소하고 있는 추세이 다(4). 또한 FTA 체결로 인한 쌀의 수입물량 및 생산량 증가 등의 문제로 신 수요창출을 위한 노력이 지속적으로 필요한 상황이다(5).

쌀을 이용한 주류 개발은 탁주를 중심으로 연구 및 개발 되어져왔고 맥주에 부원료로 적용하기 위한 연구가 일부 시도된 바 있다. Kwon 등(6)은 맥주의 제조과정 중 당화정 도에 따라 당도가 결정되고, 이에 따라 알코올 함량에 영향 을 미치게 되는데 쌀을 첨가하게 된다면 당화효율이 크게 떨어져 이를 개선하기 위한 연구가 필요하다고 보고하였 다. Hyun 등(7)의 연구결과에 따르면 맥주에 쌀을 첨가하게 되면 당도가 떨어지는 것을 보완하기 위하여 아밀라아제를 첨가하여 제조한 결과 당도는 증가하였으나 혼탁도가 증가 하였다고 발표하였다. 최근 해외에서 쌀을 활용하여 맥주 를 만들기 위해 쌀로 malt를 제조하여 맥주를 제조하거나 (8), 쌀맥주의 발효과정을 개선하기 위해 미생물 스타터를 활용(9)하는 등의 다양한 연구사례가 발표되고 있다. 그러 
나 기존에 발표된 연구결과는 쌀을 맥주 가공에 적용하기 위한 가공 및 품질특성에 관한 연구가 중심이었고, 쌀맥주 를 제조하는데 적합한 벼 품종에 선정에 관한 연구는 이루 어지지 않았다. 최근 본 연구팀은 연질미가 일반미보다 쌀 맥주 제조에 용이하며 한가루 품종으로 현미 $40 \%$ 를 첨가한 쌀맥주 제조공정을 확립하여 발표한 바 있다 $(10,11)$. 하지 만 쌀맥주의 생산 및 소비를 활성화하기 위해서는 소비자가 선호하고 맥주의 품질이 우수한 쌀과 맥아의 최적 혼합비율 선정이 필요한 상황이다.

따라서 본 연구에서는 쌀맥주에 적합한 쌀의 첨가비율을 선정하기 위한 기초자료를 확보하고자 연질미인 한가루 품종을 이용하여 첨가비율에 따라 맥주를 제조하고 품질특 성을 비교분석하였다.

\section{재료 및 방법}

\section{실험재료}

본 연구에 사용된 쌀은 2015년에 농촌진흥청 국립식량과 학원 중부작물부에서 재배 및 수확한 한가루 품종을 사용하 였으며, 수확한 정조는 제현기(Model SY88-TH, Ssangyong Ltd., Incheon, Korea)를 이용하여 왕겨를 분리한 현미를 시험재료로 사용하였다. 맥아는 광맥(Kwangmaeg, Gochang $\mathrm{GDC}$, Gochang, Korea)을 사용하였다. 맥주 제조에 필요한 홉은 cascade 및 centennial(Hopunion, Yakima, WA, USA)를 혼합하여 사용하였으며, 효모는 건조된 에일용 효모 (SAFALE US-05 Dry Ale Yeast, Algist Bruggenman, Gand, Belgium)를 사용하였다. 쌀 첨가비율별로 제조한 맥주의 품질평가를 위하여 쌀이 $30 \%$ 첨가된 시판 수입맥주를 대조 군으로 분석하였다.

\section{쌀맥주 제조}

쌀맥주 제조는 본 연구팀에서 발표한 공정을 토대로 제 조하였다 $(1,10)$. 즉, 맥아 $5 \mathrm{~kg}$ 을 이용하여 $100 \%$ 맥아로 제조한 맥주와 맥아의 일부를 한가루 현미로 대체하여 쌀의 첨가량을 $10 \%$ (현미:맥아 $=0.5: 4.5 \mathrm{~kg}$ ), $20 \%$ (현미:맥아 $=1.0: 4.0 \mathrm{~kg}$ ), 30\%(현미:맥아=1.5:3.5 kg) 및 40\%(현미:맥아 $=2.0: 3.0 \mathrm{~kg}$ ) 비율로 혼합하여 제조한 맥주를 이용하여 실험 을 수행하였다. 현미의 액화를 위해 비율별 첨가량의 현미 와 맥아를 $1.0: 0.3$ 의 비율로 혼합 후 $90^{\circ} \mathrm{C}$ 식수 $10 \mathrm{~L}$ 를 이용 하여 40 분 동안 액화를 진행하였다. 그 후 당화과정을 위하 여 잔량의 맥아 비율별로 첨가한 다음 $68^{\circ} \mathrm{C}$ 에서 $78^{\circ} \mathrm{C}$ 로 승온하여 1 시간 동안 반응 후 당화액을 얻었고 $20 \mathrm{~L}$ 로 부피 를 맞추었다. 그 다음 $100^{\circ} \mathrm{C}$ 에서 60 분 동안 끓임 단계 중에 홉 $2 \%(40 \mathrm{~g}, \mathrm{w} / \mathrm{v})$ 을 반응 시작 15 분 후 및 반응 종료 10 분 전에 나누어서 첨가하였다. 끓인 맥즙을 냉각한 다음 발효 조에 옮겨 담은 후 효모를 당화액을 기준으로 $0.58 \%(11.5$ $\mathrm{g}, \mathrm{w} / \mathrm{v})$ 을 첨가하여 발효과정을 $20^{\circ} \mathrm{C}$ 에서 7 일간 진행하였 다. 발효 후 효모 제거를 위해 여과를 진행한 다음 얻어진 맥주 $20 \mathrm{~L}$ 를 $2^{\circ} \mathrm{C}$ 에서 약 1.5-2달간 숙성하여 실험에 사용하 였다.

\section{알코올 및 가용성 고형분 함량}

쌀 첨가비율에 따라 제조한 맥주의 알코올 함량은 증류 법(11)으로 분석하였으며, 증류 후 알코올-온도 보정표에서 $15^{\circ} \mathrm{C}$ 로 보정한 알코올 함량을 표준 보정곡선에 대입하여 알코올 함량 $(\%, \mathrm{v} / \mathrm{v})$ 을 계산하였다. 가용성 고형분 함량은 시료액을 취하여 당도계(PAL-3, ATAGO, Tokyo, Japan)를 이용하여 분석하였다.

\section{$\mathrm{pH}$ 및 산도}

$\mathrm{pH}$ 는 $\mathrm{pH}$ meter기(Model 750, iSTEC, Seoul, Korea)로 측 정하였고, 산도는 시료 $10 \mathrm{~mL}$ 에 $0.1 \mathrm{~N} \mathrm{NaOH}$ 용액을 넣어 $\mathrm{pH}$ 8.2가 될 때까지 소비된 $\mathrm{NaOH}$ 의 용량 $(\mathrm{mL})$ 을 측정하여 아래의 식을 이용하여 젖산 함량으로 환산하였다.

Total acidity $(\%$ lactic acid $)=\frac{0.009 \times 0.1 \mathrm{~N} \mathrm{NaOH}(\mathrm{mL}) \times \mathrm{F}}{\text { Sample }(\mathrm{g})} \times 100$

$$
\mathrm{F}: 0.1 \mathrm{~N} \mathrm{NaOH} \text { 의 역가(F=1.002) }
$$

아미노산도

맥주의 아미노산도는 시료 $10 \mathrm{~mL}$ 를 $100 \mathrm{~mL}$ 삼각플라스 크에 취한 다음, 페놀프탈레인 지시약 2-3방울을 가하여 $0.1 \mathrm{~N} \mathrm{NaOH}$ 용액으로 엷은 분홍색이 나올 때까지 적정하였 다. 여기에 중성포르말린 용액 $5 \mathrm{~mL}$ 를 넣어 원래의 색이 나오게 한 다음 다시 $0.1 \mathrm{~N} \mathrm{NaOH}$ 용액으로 엷은 분홍색이 나올 때까지 적정하여 소비된 용액의 양을 아미노산도로 표시하였다.

\section{아미노산도 $=\mathrm{A} \times \mathrm{F}$}

Glycine 산출 $(\mathrm{g} / 100 \mathrm{~mL})=$ 아미노산도 $\times 0.0075 \times 10$

\section{색도}

쌀 첨가비율별 맥주의 색도 변화를 측정하기 위해 시료 를 $50 \mathrm{~mm}$ 의 투명용기에 옮겨 담은 후 Color Differencemeter (CM-3500d, Konica Minolta Sensing, Osaka, Japan)를 이용 하여 측정하였다. 기계는 측정 전 표준흑판과 표준백판을 표준화한 후 사용하였으며 명도(L ${ }^{*}$, lightness $)$, 적색도(a*, redness) 및 황색도( $b^{*}$, yellowness)값으로 나타내었다. 측정 된 값은 Spectra Magic Software(Minolta Cyber Chrom Inc., Osaka, Japan)를 이용하여 기록하였다.

\section{쓴맛}

맥주의 쓴맛(BU, Bitterness unit) 측정은 국세청 주류분석 
규정을 토대로 분석하였다(12). 쌀 첨가비율별로 제조한 맥주를 거품의 손실이 없도록 가스를 제거하여 $20^{\circ} \mathrm{C}$ 로 조절 하고 $10 \mathrm{~mL}$ 을 원심관에 취한 후 $6 \mathrm{~N}$ 염산 $0.5 \mathrm{~mL}$, 이소옥탄 $20 \mathrm{~mL}$ 를 가하여 밀봉한 다음 진탕기를 $250 \mathrm{rpm}$ 에서 15 분간 방치하였다. $3,000 \mathrm{rpm}$ 에서 3 분간 원심분리 후 이소옥탄 층을 $10 \mathrm{~mm}$ 셀에 취한 다음 $275 \mathrm{~nm}$ 에서 흡광도를 측정한 후 아래의 식에 대입하여 계산하였다.

$$
\text { 쓴맛 }=\text { 흡광도 } \times 50
$$

\section{통계분석}

본 시험에서 얻어진 결과는 SPSS 12.0(Statistical Package for Social Sciences, SPSS Inc., Chicago, IL, USA) program을 사용하여 각 실험구간의 유의성을 검증한 후 Duncan's multiple range tests에 의해 실험군간의 차이를 $5 \%$ 유의수준 에서 분석하였다.

\section{결과 및 고찰}

\section{알코올 및 가용성 고형분 함량}

쌀 첨가비율에 따른 맥주의 알코올 함량을 측정한 결과 3.93-4.40\%로 나타났다(Table 1). 대조군으로 사용한 쌀이 첨가된 시판 수입맥주 $(4.53 \%)$ 보다는 낮게 나타났지만, 시 판되고 있는 페일에일 맥주의 알코올 함량이 4.1-4.6\% 범위 로 측정되었다는 결과(13)와 유사하였다.

가용성 고형분 함량은 주류의 향기와 단맛에 영향을 주 는 주요 성분이며, 전분질 원료는 당화효소에 의해 당분으 로 분해됨과 동시에 효모의 영양원이나 발효기질로 이용되 므로 효모의 에탄올 생산을 결정짓는 요인이다(14). 쌀 첨가 비율별로 제조한 맥주의 가용성 고형분 함량은 6.20-6.97 ${ }^{\circ} \mathrm{Brix}$ 로 쌀 첨가비율이 많을수록 증가하였으며, 대조군으 로 사용한 쌀이 첨가된 시판 수입맥주(5.30 $\left.{ }^{\circ} \mathrm{Brix}\right)$ 보다는

Table 1. Alcohol and total soluble solid contents of beer containing various percent of rice

\begin{tabular}{ccc}
\hline Sample & Alcohol content $(\%)$ & Total soluble solid content ( ${ }^{\circ}$ Brix $)$ \\
\hline Control $^{1)}$ & $4.53 \pm 0.12^{2 / \mathrm{a} 3)}$ & $5.30 \pm 0.00^{\mathrm{d}}$ \\
$0 \%$ & $4.40 \pm 0.00^{\mathrm{b}}$ & $6.37 \pm 0.06^{\mathrm{b}}$ \\
$10 \%$ & $4.10 \pm 0.00^{\mathrm{c}}$ & $6.20 \pm 0.00^{\mathrm{c}}$ \\
$20 \%$ & $4.13 \pm 0.12^{\mathrm{c}}$ & $6.20 \pm 0.00^{\mathrm{c}}$ \\
$30 \%$ & $3.93 \pm 0.06^{\mathrm{d}}$ & $6.33 \pm 0.06^{\mathrm{b}}$ \\
$40 \%$ & $4.23 \pm 0.06^{\mathrm{c}}$ & $6.97 \pm 0.06^{\mathrm{a}}$ \\
SEM $^{2}$ & 0.061 & 0.033
\end{tabular}

${ }^{1)}$ The commercial beer containing about $30 \%$ of rice was remarked irrespective of own brand.

${ }^{2)}$ Standard errors of the mean $(n=3)$.

3)-d Different letters within the same column indicate significant differences $(\mathrm{p}<0.05)$.
높게 측정되었다(Table 1). 이는 쌀의 함량이 증가할수록 ${ }^{\circ} \mathrm{Brix}$ 가 감소하는 경향을 보였다는 결과(7)와 상이하였다. 일반적으로 맥주 제조 시 공정상에서 맥즙의 여과 과정을 1-2회 거친 반면 본 연구에서 사용한 시료는 효모 제거를 위한 여과 공정을 제외한 맥즙의 여과 공정을 따로 거치지 않아 원료에 잔류한 당의 영향인 것으로 판단된다. 그러나 숙성 완료된 맥주의 환원당 함량은 2.23-2.29\%로 쌀 첨가량 에 의한 함량에 의한 큰 차이는 관찰되지 않았다(data not shown). 추후 쌀 첨가에 의한 액화, 당화, 발효 및 숙성 단계 별 유리당 및 아미노산 등의 성분 분석 등을 통해 쌀 첨가로 인하여 생성되는 지표물질에 대한 분석이 요구된다.

\section{$\mathrm{pH}$, 산도 및 아미노산도}

맥주의 $\mathrm{pH}$ 는 맛, 물리적 및 미생물학적 안정성에 영향을 주고 효모의 성장과 맥아즙 완충 능력을 자국하고 맥주의 맛, 잠재적인 혼탁 안정성을 주는 것으로 알려져 있으며 (15), 당화 효소 또는 단백질 분해 효소의 작용과 홉의 쓴맛 성분의 용출 등 공정에서 중요한 요소라고 할 수 있다(2). 본 연구결과 맥주의 $\mathrm{pH}$ 는 4.32-4.60의 범위로 나타났으며, 쌀 첨가비율 및 대조군과의 유의적인 차이는 관찰되지 않았 다(Table 2). Sung과 Lee(2)는 시판 중인 12종의 상면발효맥 주의 $\mathrm{pH}$ 가 3.71-4.78로 나타났으며 이는 맥주의 원료 및 제조공정 등에 따른 결과라고 보고하였다.

쌀 첨가비율에 따른 맥주의 산도 및 아미노산도를 측정 한 결과 쌀 첨가비율에 따라 낮아지는 경향을 보였다(Table 2). 산도는 주류의 풍미와 저장성에 영향을 미치는 인자로 서 발효가 진행되면서 효모 등의 미생물 작용으로 생성된 다양한 유기산에 영향을 받는 것으로 알려져 있다(16). 본 실험에서 맥주의 $\mathrm{pH}$ 와 총산의 함량이 비례적이지 않게 나 타났는데, 이는 맥주의 발효과정에서 단백질이 분해되면서 펩티드와 아미노산이 증가하여 완충작용을 높여주기 때문 인 것으로 판단된다(5). 아미노산도는 원료에 포함된 단백 질이 acidic protease와 기타 peptidase 등의 분해효소 작용에

Table 2. pH, total acidity and amino-acidity of beer containing various percent of rice

\begin{tabular}{cccc}
\hline Sample & $\mathrm{pH}$ & $\begin{array}{c}\text { Total acidity } \\
(\%, \text { lactic acid value })\end{array}$ & $\begin{array}{c}\text { Amino-acidity } \\
(\%, \text { amino acid value })\end{array}$ \\
\hline Control $^{1)}$ & $4.43 \pm 0.10^{2)}$ & $0.28 \pm 0.00^{\mathrm{a3})}$ & $0.01 \pm 0.00^{\mathrm{d}}$ \\
$0 \%$ & $4.54 \pm 0.03$ & $0.22 \pm 0.02^{\mathrm{bc}}$ & $0.08 \pm 0.01^{\mathrm{a}}$ \\
$10 \%$ & $4.38 \pm 0.29$ & $0.22 \pm 0.19^{\mathrm{bc}}$ & $0.03 \pm 0.00^{\mathrm{c}}$ \\
$20 \%$ & $4.45 \pm 0.23$ & $0.24 \pm 0.16^{\mathrm{b}}$ & $0.04 \pm 0.00^{\mathrm{b}}$ \\
$30 \%$ & $4.55 \pm 0.30$ & $0.22 \pm 0.08^{\mathrm{bc}}$ & $0.04 \pm 0.00^{\mathrm{b}}$ \\
$40 \%$ & $4.32 \pm 0.20$ & $0.21 \pm 0.15^{\mathrm{c}}$ & $0.04 \pm 0.00^{\mathrm{b}}$ \\
$\mathrm{SEM}^{2}$ & 0.176 & 0.009 & 0.003 \\
\hline
\end{tabular}

${ }^{1)}$ Control indicates the commercial beer prepared by the addition about $30 \%$ of rice. ${ }^{2)}$ Standard errors of the mean $(n=3)$.

3)-d Different letters within the same column indicate significant differences $(\mathrm{p}<0.05)$. 
의해 유리되는 아미노산을 측정한 수치로서 적당량의 유리 아미노산은 주류에 감칠맛을 부여하여 기호도에 긍정적인 영향을 준다(14,17). 본 실험 결과 쌀을 첨가한 맥주가 $100 \%$ 맥아로 제조한 맥주보다 아미노산도가 낮게 측정되었으나 시판 맥주와는 유사한 결과를 보인 것으로 보아 맥주 제조 에 사용하는 주원료에 함유된 단백질과 구성 아미노산 및 부원료의 특성 차이로 판단되나, 이를 명확하게 구명하기 위한 후속연구가 필요하다고 판단된다.

\section{색도}

쌀 첨가비율에 따른 맥주의 색도 측정결과를 Table 3에 제시하였다. 쌀 첨가비율이 증가할수록 명도는 증가한 반 면 적색도 및 황색도는 감소하는 경향을 보였다. 명도의 경우 대조군보다 값이 낮게 나타났으며 적색도 및 황색도는 높게 측정되었다. 본 연구에서 사용한 쌀은 한가루 품종의 현미이며, 동일한 품종의 백미로 맥주를 제조하게 되면 현 미로 제조한 품종보다 명도가 크게 증가하였다(data not shown). 맥주의 색도는 원료, 양조용수, 맥즙 제조공정 및 발효공정 등에 영향을 받아 페놀화합물 및 메일라드 반응에 의하여 변화한다고 알려져 있으며(2), 맥주 제조 시 끓이는 과정에서 원료곡 및 홉에서 유래한 폴리페놀이 산화되어

Table 3. Hunter color values of beer containing various percent of rice

\begin{tabular}{cccc}
\hline Sample & $\mathrm{L}^{*}$ & $\mathrm{a}^{*}$ & $\mathrm{~b}^{*}$ \\
\hline Control $^{1)}$ & $96.38 \pm 0.01^{\mathrm{a} 2)}$ & $-2.02 \pm 0.00^{\mathrm{f}}$ & $19.23 \pm 0.01^{\mathrm{f}}$ \\
$0 \%$ & $87.35 \pm 0.00^{\mathrm{f}}$ & $1.51 \pm 0.00^{\mathrm{a}}$ & $44.27 \pm 0.01^{\mathrm{a}}$ \\
$10 \%$ & $87.81 \pm 0.00^{\mathrm{e}}$ & $1.15 \pm 0.01^{\mathrm{b}}$ & $40.46 \pm 0.01^{\mathrm{b}}$ \\
$20 \%$ & $88.86 \pm 0.04^{\mathrm{d}}$ & $1.02 \pm 0.00^{\mathrm{c}}$ & $39.68 \pm 0.12^{\mathrm{c}}$ \\
$30 \%$ & $89.10 \pm 0.01^{\mathrm{c}}$ & $0.91 \pm 0.03^{\mathrm{d}}$ & $38.16 \pm 0.04^{\mathrm{d}}$ \\
$40 \%$ & $89.61 \pm 0.02^{\mathrm{b}}$ & $0.59 \pm 0.02^{\mathrm{e}}$ & $37.70 \pm 0.08^{\mathrm{e}}$ \\
SEM2 & 0.015 & 0.012 & 0.050 \\
\hline
\end{tabular}

${ }^{1)}$ Control indicates the commercial beer prepared by the addition about $30 \%$ of rice.

2)af Different letters within the same column indicate significant differences $(\mathrm{p}<0.05)$.
숙성 및 저장기간 과정에서 맥주의 색 형성에 영향을 주는 것으로 보고되고 있다 $(18,19)$.

\section{쓴맛}

쌀 첨가비율별로 제조한 맥주의 쓴맛을 측정한 결과 대 조군으로 사용한 시판 쌀 첨가 맥주보다는 쓴맛의 강도가 높았으나, 쌀 첨가비율이 증가할수록 쓴맛의 강도는 감소 하는 것으로 나타났다(Fig. 1). 관능검사 결과 쌀 첨가비율 이 높을수록 맥주의 쓴맛이 감소하고, 부드러운 맛이 증가 하였다는 결과와 유사하였다(data not shown). Kwon 등(6) 의 보고에 따르면 맥주 제조 시 효소첨가로 인해 생성된 당 성분 함량의 증가와 함께 단백질 분해로 인해 쓴맛이 상쇄되었다고 발표하였다. 맥주 품질에서 나타내는 쓴맛 정도는 주로 홉에서 나오는 유도체인 iso- $a$ acid 함량에 따라 나타나며, 맥주의 쓴맛은 iso-octane으로 산성화되어 추출 된 bitter substances를 측정하여 결정하게 된다(20). 미국의 라이트 라거 맥주는 일반적으로 생산되는 맥주 중 가장 낮은 BU 수준을 가지는데, 쓴맛을 느끼기 시작하는 맛의

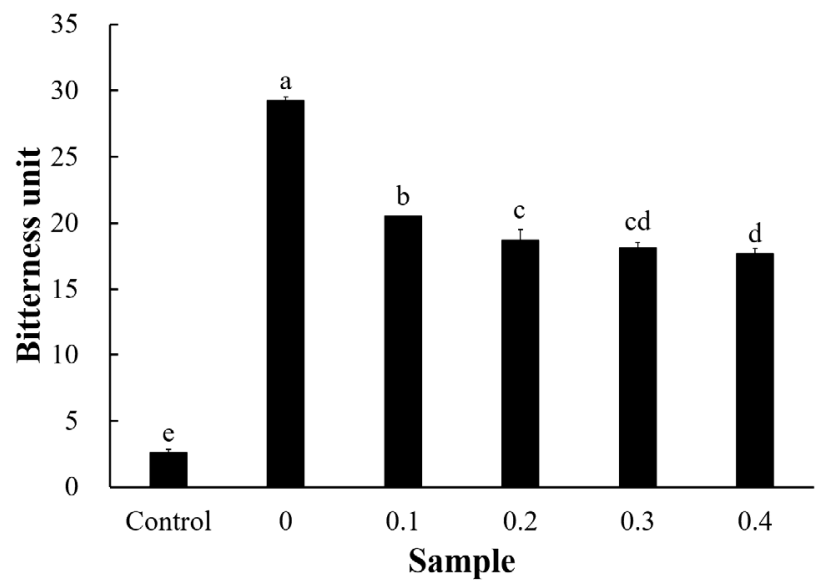

Fig. 1. Bitterness of beer containing various amounts of rice.

Control indicates the commercial beer prepared by the addition about $30 \%$ of rice. ${ }^{a-e}$ Different letters indicate significant differences $(p<0.05)$.

Table 4. The correlation of factors affecting quality characteristics of rice beer

\begin{tabular}{ccccccccc}
\hline Factor & Total sugar content & $\mathrm{pH}$ & Acidity & Amino acidity & Bitterness & L-Value & a-Value & b-Value \\
\hline Alcohol content & $0.2972^{\mathrm{NSl}}$ & $0.1232^{\mathrm{NS}}$ & $-0.0545^{\mathrm{NS}}$ & $0.6831^{* *}$ & $0.7140^{* *}$ & $-0.4352^{\mathrm{NS}}$ & $0.4262^{\mathrm{NS}}$ & $0.6585^{* *}$ \\
Total sugar content & 1.0000 & $-0.1960^{\mathrm{NS}}$ & $-0.4290^{\mathrm{NS}}$ & $-0.0258^{\mathrm{NS}}$ & $-0.2218^{\mathrm{NS}}$ & $0.5724^{*}$ & $-0.6440^{* *}$ & $-0.4033^{\mathrm{NS}}$ \\
$\mathrm{pH}$ & - & 1.0000 & $-0.0950^{\mathrm{NS}}$ & $0.2792^{\mathrm{NS}}$ & $0.2404^{\mathrm{NS}}$ & $-0.1560^{\mathrm{NS}}$ & $0.2489^{\mathrm{NS}}$ & $0.1879^{\mathrm{NS}}$ \\
Acidity & - & - & 1.0000 & $-0.0255^{\mathrm{NS}}$ & $-0.0474^{\mathrm{NS}}$ & $-0.0036^{\mathrm{NS}}$ & $0.1274^{\mathrm{NS}}$ & $0.0432^{\mathrm{NS}}$ \\
Amino-acidity & - & - & - & 1.0000 & $0.8754^{* * *}$ & $-0.5330^{*}$ & $0.6731^{* *}$ & $0.7892^{* * *}$ \\
Bitterness & - & - & - & - & 1.0000 & $-0.8468^{* * *}$ & $0.8806^{* * *}$ & $0.9650^{* * *}$ \\
L-Value & - & - & - & - & - & 1.0000 & $-0.9503^{* * *}$ & $-0.9220^{* * *}$ \\
a-Value & - & - & - & - & - & - & 1.0000 & $0.9519^{* * *}$ \\
\hline
\end{tabular}

${ }^{1)} \mathrm{NS}$, not significant. Significant at ${ }^{*} \mathrm{p}<0.05,{ }^{* *} \mathrm{p}<0.01, \quad{ }^{* * *} \mathrm{p}<0.001$. 
정도인 8-12 BU값을 나타내며, 영국의 페일에일의 경우45 $\mathrm{BU}$ 정도의 값을 가진다고 알려져 있다(21). 본 연구에서 제조한 맥주는 에일맥주로 쓴맛이 기존 에일맥주 범위 안에 포함된 것을 확인하였다. 보통 맥주의 쓴맛을 조절하기 위 하여 알파산 함량이 다른 홉의 사용, 홉 첨가량 조절 등의 방법을 사용하고 있으나 본 연구결과 맥주에 쌀을 첨가하게 되면 쓴맛 조절이 가능할 것으로 판단된다.

\section{쌀맥주 품질특성간의 상관관계 분석}

쌀을 첨가하여 제조한 맥주의 품질특성 간의 상관관계를 분석하여 Table 4에 제시하였다. 알코올 함량은 아미노산 도, 쓴맛, 황색도 간에 $\mathrm{r}$ 값이 각각 $0.6831(\mathrm{p}<0.01), 0.7140$ $(\mathrm{p}<0.01), 0.6835(\mathrm{p}<0.01)$ 로 상관성이 있는 것으로 확인되었 다. $\mathrm{pH}$ 및 산도는 다른 품질 특성과는 상관관계가 없는 것으로 나타났다. 아미노산도의 경우 쓴맛, 적색도, 황색도 간에 $\mathrm{r}$ 값이 각각 0.8754( $\mathrm{p}<0.001), 0.6731(\mathrm{p}<0.01), 0.7892$ $(\mathrm{p}<0.001)$ 로 높은 상관성을 보였다. 쓴맛과 명도, 적색도, 황색도 간에 $\mathrm{r}$ 값이 각각 $-0.8468(\mathrm{p}<0.001), 0.8806(\mathrm{p}<0.001)$, 0.9650(p<0.001)로 높은 상관성을 나타내었다.

\section{요 약}

본 연구는 쌀맥주에 적합한 쌀 첨가비율을 선정하기 위 해 연질미인 한가루 품종을 이용하여 첨가비율에 따라 맥주 를 제조하고 품질특성을 비교분석하였다. 쌀 첨가비율별로 제조한 맥주의 알코올 함량을 측정한 결과 $3.93-4.40 \%$ 로 나타났고, 쌀 첨가비율에 따라 가용성 고형분은 증가하는 것으로 확인되었다. $\mathrm{pH}$ 는 4.32-4.60의 범위로 나타났으며, 쌀 첨가비율에 따른 유의적인 차이는 없었다. 쌀 첨가비율 에 따라 맥주의 산도 및 아미노산도가 낮아지는 경향을 보였으며, 쌀 첨가비율이 증가할수록 명도는 증가한 반면 적색도 및 황색도는 감소하는 경향을 보였다. 특히 쌀 첨가 비율이 높을수록 쓴맛의 강도는 감소하는 것으로 나타났 다. 이상의 결과를 종합하여 볼 때, 맥주를 가공하는 데에 있어 쌀의 첨가비율이 증가할수록 쓴맛이 감소되고 색택이 개선되는 등 품질 개선의 효과를 얻었다. 본 연구결과는 쌀맥주를 대량으로 제조하는 데 있어서 품질이 우수한 최적 비율을 선정하는데 기초자료로 활용될 수 있을 것이라고 판단된다.

\section{감사의 글}

본 논문은 농촌진흥청 AGENDA 연구사업(과제번
호:PJ01211101)의 지원에 의해 이루어진 것임.

\section{References}

1. Kim HJ, Park JY, Lee SK, Park HY, Cho DH, Choi HS, Oh SK (2017) Quality characteristics of rice cultivars suitable for rice beer. Korean J Crop Sci, 62, 113-117

2. Sung SA, Lee SJ (2017) Physicochemical and sensory characteristics of commercial top-fermented beers. Korean J Food Sci Technol, 49, 35-43

3. Cho JP, Lee DM, Jeong JS, Moon JH (2014) The factors of consumers' taste preferences for beer and change in attitude: Focusing on Korean consumers' preference for imported beer. J Foodserv Manag Soc Korea, 17, 7-30

4. Shin DS, Choi YJ, Sim EY, Oh SK, Kim SJ, Lee SK, Woo KS, Kim HJ, Park HY (2016) Comparison of the hydration, gelatinization and saccharification properties of processing type rice for beverage development. Korean J Food Nutr, 29, 618-627

5. Shin DS, Jeong ST, Sim EY, Lee SK, Kim HJ, Woo KS, Oh SK, Kim SJ, Park HY (2017) Quality characteristics of mixed Makgeolli with barley and wheat by fermentation temperature. Korean J Food Nutr, 30, 305-311

6. Kwon YA, Lee KG, Hong GW, Lee SJ (2012) Improving qualities of rice beer using enzyme and amino acids. Food Eng Prog, 16, 151-156

7. Hyun SK, Kwon YA, Lee SJ (2012) Quality characteristics of brewed beer with rice adjunct. Food Eng Prog, 16, 139-144

8. Mayer HM, Ceccaroni D, Marconi O, Sileoni V, Perretti G, Fantozzi P (2016) Development of an all rice malt beer: A gluten free alternative. LWT-Food Sci Technol, 67, 67-73

9. Das AJ, Khawas P, Miyaji T, Deka SC (2014) Effect of various microbial starters for amylolytic fermentation on some quality attributes of rice beer. Int Food Res J, 21, 2443-2450

10. Rural Development Administration (2016) Process for preparing rice beer using soft rice. Korea Patent No. 10-2016-0169787

11. Ha SJ, Yang SK, In YW, Kim YJ, Oh SW (2012) Changes in microbial and physicochemical properties of single-brewed Makgeolli by high hydrostatic pressure treatment during fermentation. J Korean Soc Food Sci Nutr, 41, 1176-1181 
12. NTS Liquors Licence Aid Center (2008) Analysis of Liquor Regulatory. Liquors Licence Aid Center, Seoul, Korea, p 1-68

13. Kim KH, Park SJ, Kim JE, Dong H, Park IS, Lee JH, Hyun SY, Noh BS (2013) Assessment of physicochemical characteristics among different types of pale ale beer. Korean J Food Sci Technol, 45, 142-147

14. Choi JH, Jeon JA, Jung ST, Park JH, Park SY, Lee CH, Kim TJ, Choi HS, Yeo SH (2011) Quality characteristics of Seoktanju fermented by using different commercial Nuruks. Korean J Microbial Biotechnol, 39, 56-62

15. Kaneda H, Takashio M, Tamaki T, Osawa T (1997) Influence of $\mathrm{pH}$ on flavour staling during beer storage. J Inst Brew, 103, 21-23

16. Sim EY, Lee SK, Woo KS, Kim HJ, Kang CS, Kim SJ, Oh SK, Park HY (2016) The quality characteristics of wheat-Makgeolli made from different cultivars and milling rates. Korean J Food Nutr, 29, 777-784
17. Song YR, Lim BU, Song GS, Baik SH (2015) Quality characteristics and antioxidant activity of Makgeolli supplemented with Omija berries (Schizandra Chinensis Baillon). Korean J Food Sci Technol, 47, 328-335

18. Granato D, Branco GF, Faria JFA, Cruz AG (2011) Characterization of Brazilian lager and brown ale beers based on color, phenolic compounds, and antioxidant activity using chemometrics. J Sci Food Agric, 91, 563-571

19. Szabo E, Borbely M, Sipos P, Cornelia P, Adriana C (2013) Analysis of total polyphenol comtemts and colour of brewed beer samples. University of Oradea Publishing House, Oradea, Romania, p 373-377

20. Kim JH, Kim JH, Lee SJ, Hong KW, Kwon YA, Park JC, Kim WJ (2013) Characterization of fermentation kinetics of beer made of Korean 6 row-barley. Food Eng Prog, 17, 189-197

21. Lee JD (2005) Designing great beers. Life Science, Seoul, Korea, p 90-96 